\title{
За някои топоси, свързани с женските роли, в текста на книга Царства
}

\author{
Мария ТотомановА-ПаневА \\ Софийски университет „Св. Климент Охридски” (Bulgaria) \\ m_totomanova@abv.bg
}

Recibido: Mayo de 2014

Aceptado: Noviembre de 2014

\section{Резюме}

Статията се занимава със славянския превод на няколко топоса, свързани с разбирането на женските роли, в Първа и Втора книга Царства. За целите на сравнението основният ръкопис (Архивският хронограф) е съпоставен с още седем славянски ръкописа, извлечението от Книги Царства в Славянската версия на Хрониката на Георги Синкел, Острожката библия, както и с текста на Септуагинта и Вулгата. Въз основа на събрания богат речников и изворов материал, статията анализира и търси причината за необичайните преводачески решения на старобългарския книжовник.

Ключови думи: Стар Завет, Книги Царства 1-2, топоси, женски роли.

Sobre algunos tópicos relacionados con el rol femenino en el texto del Libro de los Reyes

\section{Resumen}

El artículo estudia la traducción eslava de una serie de topos relacionados con la comprensión de los roles femeninos en los Libros I y II de Reyes. Para los fines de la investigación el manuscrito principal (El Cronógrafo de Archivo) se compara con otros siete manuscritos eslavos, la excepción de los Reyes en la versión eslava de la Crónica de Jorge Sincelo y de la Biblia Ostrožka, así como con los textos de la Septuaginta y de la Vulgata. A base de las fuentes y el rico material lexicográfico recopilado el artículo analiza las decisiones de traducción poco convencionales del traductor búlgaro medieval y busca sus razones.

Palabras clave: Viejo Testamento, Libros I y II de los Reyes, tópicos, roles femeninos.

\section{On some topoi connected with female roles in the Books of Samuel}

\begin{abstract}
The article focuses on the Slavonic translation of several topoi connected with the understanding of female roles in the Old Testament books of Samuel I and II. For the purposes of the comparison the main manuscript (the Chronograph of the Archives) was confronted with another seven Slavonic manuscripts, containing the aforementioned biblical books, with the respective excerpts in the Slavonic Version of the Chronicle of George Synkellos, the Ostrog Bible, as well as with the Septuagint and the Vulgate. On the basis of the collected material the article explores the unusual metaphrastic decisions of the Old Bulgarian translator.
\end{abstract}

Key words: Old Testament, Samuel I-II, topoi, female roles. 
Още в края на XIX в. при описанието на славянските ръкописи в Московската синодална библиотека Горски и Невоструев отбелязват, че преводът на Книги Царства е с най-неудовлетворително качество сред преводите в Генадиевския свод от 1499 г. и че това рязко го отличава от превода на Осмокнижието. Те посочват, че липсва сходство в превода на едни и същи думи и следователно преводачът на Осмокнижието и на Царства не е едно и също лице, а преводът на Царства се явява по-късен от този на Осмокнижието, въпреки че показва редица древни черти (ГОРСКИЙ, НЕВОСТРУЕВ 1855: 3441). За древността на превода на Книги Царства говори и Соболевски, който проучва Първа и Втора книга по най-ранния препис (РНБ, СПб, F.I.461, XIV в.) и нарича превода им Методиевски (СОБОЛЕВСКИЙ 1900). Михайлов (МИХАЙЛОВ 1912: СССІ-СССІІ) смята, че Соболевски твърде много се доверява на свидетелството в 15 глава на житието на Св. Методий, но все пак споделя неговото мнение. Спорът дали преводът на Стария завет като цяло и в частност на Книги Царства може да е дело на Св. Методий и до днес разделя мненията на палеославистите. Сред основните поддръжници на хипотезата за пълен Методиев превод на Светото писание са Д. Дунков и Св. Николова. Изследвайки текста в ръкопис F.I.461, Дунков (ДУНКОВ 1991: 35, 37) заключава, че той се отнася към древен превод от края на IX в. и допуска, че отделни части от книгата са преведени или допълнени и редактирани от български книжовници в края на IX-началото на Х в. Св. Николова (НИКОЛОВА 1994: 118) отбелязва, че преводът в най-ранния известен български ръкопис е много древен и в основата му е залегнал преводът, подготвен от Методий и учениците му, но същевременно текстьт пази следи от по-късни редакции от X и XIV в. Фр. Томсън отхвърля по-горните хипотези с довода, че предвид изобилието от грешки не е възможно да говорим за Методиев превод и че липсват следи от различни преводачески техники в отделните пасажи. Според изследователя хипотезата за редакция от XIV в. също трябва да бъде отхвърлена, тъй като никой от ръкописите не показва следи от редактиране спрямо Евтимиевите реформи (THOMSON 1998: 758). Руският учен А. Алексеев (АЛЕКСЕЕВ 1999: 155) също е склонен да отнесе превода на Книги Царства към библейските текстове, достигнали до нас в Методиев превод, но с някои уговорки. Преводът на Книги Царства в Архивния хронограф (РГАДА, Москва, ф. 181, 279/658, края на XV в.) съвпада с превода в използваните руски и среднобългарски ръкописи. Древността му се подкрепя и от отбелязаното от Т. Славова (СЛАBOBA 2011) наличие на глаголически букви в текста, както и от многобройните архаични и редки лексеми, hapax legomena и прабългаризми. До момента обаче събраният при съпоставката на ръкописите материал не говори за наличие на моравски черти, а по-скоро потвърждава изказаната от Нахтигал теза, че „перевод книг Царства... не может быть никоим образом и произведением болгарской школы, которой принадлежит перевод толковых пророчеств и вероятно, и Осмикнижия. Такой памятник мог появиться напр. в (западной) Македонии“ (НАХТИГАЛ 1902: 206).

Идеята за тази статия възникна в хода на работата ми върху проучването на текстологичната история на Книги Царства в славянската ръкописна традиция 
в хронографски и извънхронографски източници.

За текстологическото сравнение са използвани следните ръкописи на Книги Царства: Архивен хронограф (РГАДА, ф. 181, № 279/658, края на XV в. - понататък А), три среднобългарски ръкописа (РНБ, F.I.461, XIV в. - по-нататък $\mathrm{P}^{1}$; РГБ, ф. 256, Румянцев № 29, 1537 г., молдавска редакция - по-нататък R; РГБ, ф. 87, Григ. № 1/M 1684, ресавски, първа половина на XVI в. - по-нататьк $\mathrm{G)}$ и четири руски ръкописа (РГБ, ф. 173, Московска духовна академия № 12, 1470-1490 г. - по-нататък D; РНБ, Сол. № 75/75, XV-XVI в. - по-нататък S; РГБ, ф. 304.I № 728, XV в. - по-нататък Т; РГБ, ф. 310, Ундолски № 1, XV в. [1480 г.] - по-нататък U). За съпоставителния анализ са привлечени също и извлечението от Книги Царства в Славянската версия на Хрониката на Георги Синкел (ТОТОМАНОВА 2008), Острожката библия от 1581 г. (по-нататък ОБ) и Септуагинта (BROOKE, MCLEAN, THACKERAY 1927 - по-нататьк Gr).

В Архивния хронограф Книги Царства заемат листове 210a-283с (до 4Цар 23:30) и се намира непосредствено след Осмокнижието, завършващо с книга Рут (л. 199a), прочутата бележка на презвитер Григорий (л. 199a) и V книга на Хрониката на Иоан Малала (л. 199а-210a). В хода на работата ми по съпоставителното текстологическо изследване на Първа и Втора книга Царства вниманието ми бе привлечено от някои топоси, свързани с женските роли в Старозаветния свят.

На първо място ще разгледам един неправилен превод, отбелязан, но некоментиран от Кулбакин (КУЛЬБАКИН 1901: 26) Става дума за стих 1 Царства

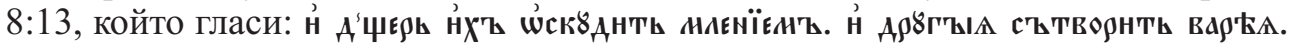

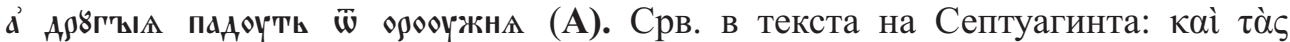

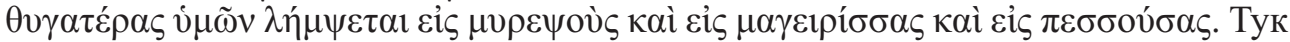
Самуил съобщава на народа, който иска от него цар, какви ще бъдат правата на този цар. Как той ще може да взема синовете им, за да бъдат войници, за да обработват нивите му и пр., а дъщерите ще вземе буквално ,да варят благовонни мазила, да готвят и пекат“. Славянският преводач неправилно е извел грьц-

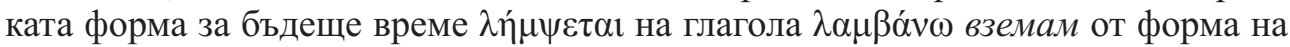
глагола $\lambda \varepsilon ß \pi \omega$ оставям, който в старобългарски редовно се предава с оскСдити. Тази грешка се повтаря системно в целия превод на първите две книги и не е плод на случайност. Първата грешка повлича след себе си и изкри-

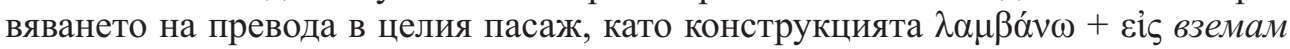
някого за нещяо, се превежда чрез глагола оскжднтн + име в творителен падеж. В южнославянските преписи името в тв. П. е оүннлєннєн'ы, което повече поДХожДа По смисъЛ От нолємнєнь, което откриваме в руските преПиси и е очевидна поправка на руските преписвачи. Така изречението придобива смисъл, че царят ще лиши дъщерите им от умиление, милост. Много интересно преводаческо решение намираме в Острожката библия, където същата конструкция

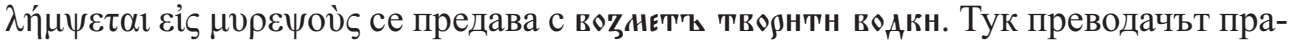
вилно е разпознал глаголната форма на $\lambda \alpha \mu \beta \alpha ́ v \omega$, но не се е сетил, че $\mu v \rho \varepsilon \psi o ́ s$ се отнася до приготвянето на благовония, което само по себе си е странно,

\footnotetext{
1 Изказвам сърдечна благодарност на проф. Светлина Николова за възможността да работя с този препис.
} 
защото думата миро е позната още в най-древните старобългарски паметници в самостоятелна употреба и като пьрва част на редица сложни думи. Срв. напр.

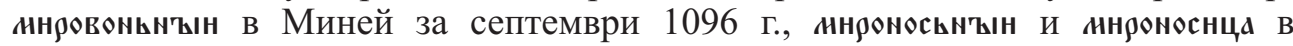
Остромировото евангелие от 1056 г. (СДРЯ II: 145, 146). Защо обаче през XVI в. в Русия са използвали водка за помазване, не знаем. Преводът в А правилно

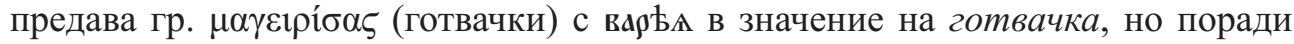
погрешно започнатото изречение добавя още един глагол - сқтвюрнты. Думата 'варяя' е запазена в руски език. Срв. у Даль (ДАЛЬ I: 165) варея ж. кто варит, готовит, стряпает; кто присматривает за варкою чего-либо. „Уха сладка, варея гладка, будто ягодка“. Близка лексема - повырї̈ - намираме в Острожката библия. Верен е и преводът в $\mathrm{G}$ - сокочмнца (f. 220r), дериват на прабългарската лексема сокдчнн готвач. Последната дума $\pi \varepsilon \sigma \sigma o v ́ \sigma \alpha$ (причастие от глагола

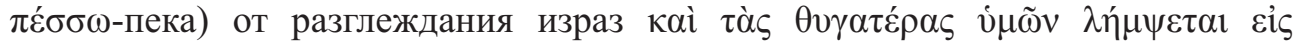

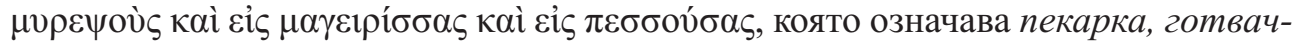
$\kappa a$, е била голямо предизвикателство за всички славянски преводачи.

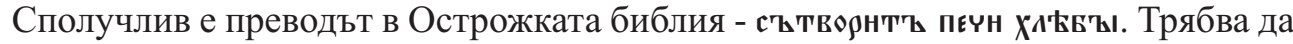
отбележим обаче, че този преводачески избор най-вероятно е повлиян от превода във Вулгатата, където намираме panifica, букв. жена, която прави хляб,

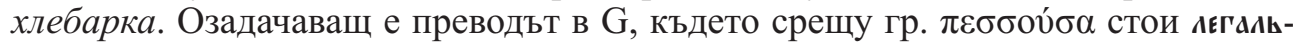
мнца спалня (СДРЯ II: 14). Възможно е в оригинала на този препис да е стояла лексемата пєчыньнца, която представлява словообразователен еквивалент на гръцката дума, в значение на жена, която пече или по-общо на жена, която се грижи за нещзо. Пєчдльннк' се намира в речниците на Срезневски (СДРЯ II: 924) и Миклошич (MIKLOSICH 1862-1865: 561) и означава застъпник, попечител. У Дал (ДАЛЬ III: 107) е засвидетелствано и съответствието от ж.р. пєчАльннца. Ако това предположение е вярно, то вариантьт лєгальннца може да е резултат от преписваческа грешка. Във всички използвани руски и среднобългарски рькописи на Царства на това място обаче намираме а дюоүг"ыА падоүты

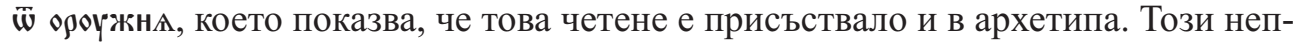
равилен превод най-вероятно се дължи на неправилно разбраната форма $\pi \varepsilon \sigma \sigma o v ́ \sigma \alpha \varsigma$ като сегашно деятелно причастие от $\pi i \tau \tau \omega$ nадам вместо от $\pi \varepsilon ́ \sigma \sigma \omega-$ пека. В този случай преводачът е почувствал нуждата да уточни от какво падат тези жени и вероятно под влияние на контекста е добавил ш̈ өююужн. Не е изключено последната грешка да е резултат от превод под диктовка, при което формите с едно или две - $\sigma-$, които различават причастията на глаголите $\pi i ́ \tau \tau \omega$ и $\pi \dot{\varepsilon} \sigma \sigma \omega$, да са звучали еднакво.

Вторият топос, на който ще спра вниманието си, е от 2 Царства 5:13: полт'

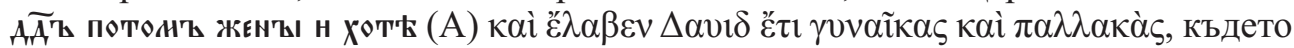
Давид, след като става цар, си взема още жени и наложници. Срещу гръцката

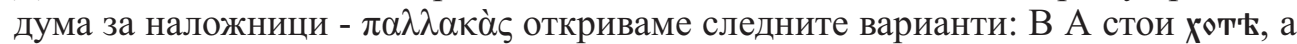
в другите руски преписи - съответно похютн DS и хотн TU. Препис G дава подсадннцн, а Острожката библия - подложннцы. И двете лексеми са засвидетелствани у Миклошич (MIKLOSICH 1862-1865: 601, 599). Интерес представлява

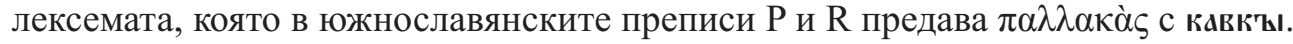
Миклошич (MIKLOSICH 1862-1865: 287) регистрира този хапакс (с вариант 
чавъка) в смисъл на amica, concubina, както и умалителното гр. каvкі́ $\zeta \alpha-$ ancilla, робиня. Други лексикографски наръчници (СРЯ 7: 11, СДРЯ I: 74) дават значение наложница и цитират същото място, като Срезневски извежда думата

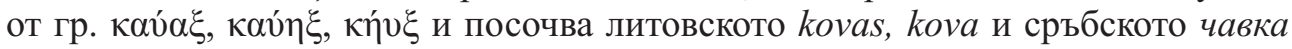
със значение чавка. В етимологичния речник на сръбския език (SKOK I: 301) думата čavka е описана като ономатопоетична, но не се регистрира употреба в значение на наложница, любовница. Подобен развой в значението обаче има италианското civetta сова (от същия звукоподражателен корен) в израза far civetta, civettare кокетирам. От друга страна етимологията на думата кокетка - жена, която се стреми да привлече мъжкото внимание с външността и маниерите си - очевидно също произлиза от име на птица. Според Фасмер (ФАСMEP II: 282) тя идва от coq петел, звукоподражателна е и се родее със стб. көкоть и көкөшь. Това доказва, че този развой в значението не е необичаен за индоевропейските езици и следователно във фразеологизма изпила ми е чавка/кукувица ума, оглупяването може да се дължи на любов към жена.

Третият топос, който ще разгледам по-нататьк, е 1 Царства 20:30, където

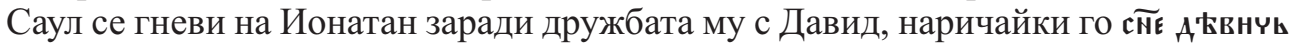

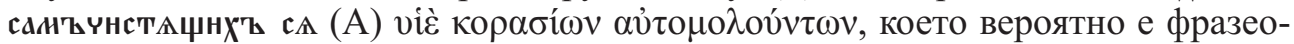
логизъм със значение сине на блуднищи, кучи сине. Преводът санъчнстАшнхты $\mathfrak{\wedge}$ на гръцкото причастие $\alpha$ $\tau о \mu о \lambda о v ́ v \tau \omega v$ откриваме във всички южнославянски и руски преписи и това очевидно е опит за калкиране на гръцката дума по познат

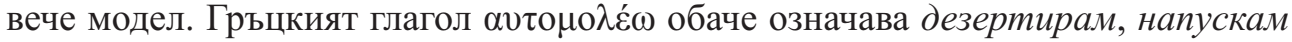
и смисълът на фразата е най-общо блудници, скитащи жени. Най-вероятно тук

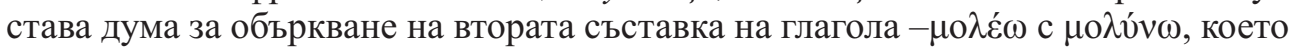

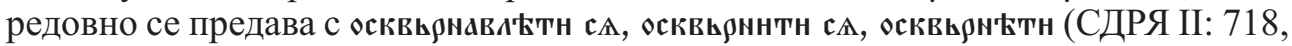
719) и то в такъв ранен паметник като сборника с 13-те слова на Григорий Богослов (по староруски препис от XI в.). Така че вероятният първоначален

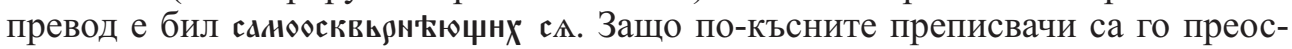
мислили и преобърнали значението на втората съставка на думата можем само

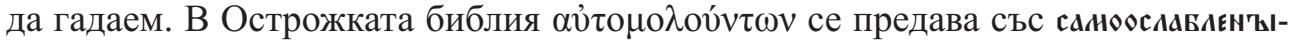

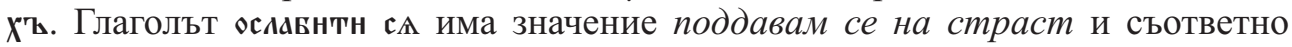

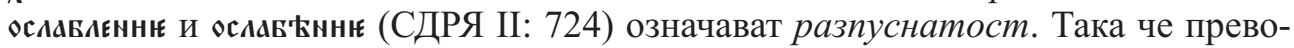
дът тук вярно предава смисъла на оригиналния текст.

Разгледаните тук преводачески решения са само малка част от топосите, които илюстрират пред какви трудности са били изправени книжовниците от IX-XI в. при сблъська си с културните реалии в старозаветния текст.

\section{Цитирана литература}

АЛЕКСЕЕВ, А. (1999): Текстология славянской Библии, Дмитрий Буланин, Санкт-Петербург.

ГОРСКИЙ, А., К. НЕВОСТРУЕВ (1855): Описание славянских рукописей Московской синодальной библиотеки, 1. Священное писание, Синодальная типография, Москва. 
ДАЛЬ, В. (1880-1882): Толковый словарь живаго великорусскаго языка, Т. 1-4., „Русский язык“, Москва, 1978-80.

ДУНКОВ, Д. (1991): „Среднобългарският препис на книгите Царства от XIV в.“, Die Slawischen Sprachen, Bd. 28, 27-41.

КУЛЬБАКИН, С. (1901): „Славянский перевод Первой книги Царств“, Сборник ОРЯС, т.68, № 3, 21-54.

МИХАЙЛОВ, А. В. (1912): Опытъ изученія книги Бытія пророка Моисея въ древнеславянскомъ переводг. Часть I. Паримейный текстъ, Типография Варшавскаго Учебнаго Округа, Варшава.

НАХТИГАЛ, Р. (1902): „Несколько заметок о следах древнеславянского паримейника в хорватско-глаголической литературе“, в Древности. Труды славянской комиссии Императорского Московского археологического общества, T. 3, 175-221.

НИКОЛОВА, С. (1994): „За най-стария средновековен ръкопис на Стария Завет“, Старобългарска литература, № 28-29, 110-118.

СЛАВОВА, Т. (2011): „Първа и втора книга Книга Царства в състава на Архивния хронограф (предварителни наблюдения)“, Palaeobulgarica, XXXV, 1, 3-16.

СОБОЛЕВСКИЙ, А (1900): “Церковно-славянские тексты моравскаго происхождения", Русский филологический вестник, Т. 43, 150-217.

СРЯ (1975-2002): Словарь русского языка XI-XVII вв. Т. 1-26. Наука, Москва.

СДРЯ (1893-1903): Срезневский, И. Материаль для словаря древне-русского языка по письменным памятникам, Т. 1-3. Типография Императорской Академии Наук, Санкт-Петербург.

TOTOMAHOBA, А (2008): Славянската версия на Хрониката на Георги Синкел, Университетско издателство “Св. Климент Охридски”, София

ФАСМЕР, М. (1986-1987): Этимологический словарь русского языка, Прогресс, Т. 1-4. Москва.

BROOKE, MCLEAN, THACKERAY (1927): The Old Testament in Greek, according to the text of Codex Vaticanus, Vol. 2., Cambridge University Press, London.

DUNKOV, D (1995): Die Methodbibel. Die Bücher der Könige. Das erste Buch Samuel-Die Slawischen Sprachen, Band 42.

DUNKOV, D (1995): Die Bücher der Könige. Das zweite Buch Samuel-Die Slawischen Sprachen, Band 45.

MIKLOSICH, F. (1862-1865): Lexicon palaeoslovenico-graeco-latinum, Scientia Verlag Aalen, Wien.

SKOK P. (1971,1972): Etimologijski rječnik hrvatskoga ili srpskoga jezika, Jugoslavenska akademija znanosti i umjatnosti, Zagreb.

THOMSON, F. (1998) The Slavonic Translation of the Old Testament, Interpretation of the Bible, Sheffield Academic Press, Sheffield, 605-920.

\section{СЪКРАЩЕНИЯ}

РГАДА - Российский государственный архив древних актов, Москва

РГБ - Российская государственная библиотека, Москва

РНБ - Российская национальная библиотека, Санкт-Петербург 